\title{
The Nature and Function of Neologism in the Speech of Three Persian-Speaking Groups
}

\author{
Fereshteh Momeni ${ }^{1}$, Shahla Raghibdoust ${ }^{2} \&$ Robab Teymouri ${ }^{3}$ \\ ${ }^{1}$ Department of Persian Literature \& Language, Islamic Azad University, Chalous Branch, Chalous, Iran \\ ${ }^{2}$ Department of Linguistics, Allameh Tabataba'i University, Tehran, Iran \\ 3 Pediatric Neurorehabilitation Research Center, University of Social Welfare and Rehabilitation Sciences, \\ Tehran, Iran \\ Correspondence: Fereshteh Momeni, Department of Persian Literature \& Language, Islamic Azad University, \\ Chalous Branch, Chalous, Iran. Tel: 98-115-222-6601. E-mail: f_momeni211@yahoo.com
}

Received: June 4, 2016 Accepted: July 11, $2016 \quad$ Online Published: September 23, 2016

doi:10.5539/ijel.v6n5p92 URL: http://dx.doi.org/10.5539/ijel.v6n5p92

\begin{abstract}
Neologism is found in some psychiatric and neurological patients and some normal children but with different features. To identify the nature and find the function of neologism, this study has examined the nonwords in the speech of 3 Persian speaking groups: 2 schizophrenic individuals with positive symptoms (hallucinations, delusions and thought disorder), 2 conduction aphasic patients affected by stroke and 5 normal children, both from a linguistic and psycho-neurolinguistic perspectives. The results along with the issues of previous literature showed there are substantive linguistic, neurological and psychological differences in the neologism of the three mentioned groups. The obtained features of the neologism in the three groups have been classified and briefly defined for the objectives. Classifying the features of neologism in order to identify its nature may help to recognize it, in the case of patients as a symptom of some disorders, and in normal children as a phase of language and cognition development process.
\end{abstract}

Keywords: neologism, schizophrenia, conduction aphasia, children, language development

\section{Introduction}

\subsection{Importance of the Problem}

The term "neologism" in psychiatry is used to describe the coinage of word-like units without having any meaning except to the person who has coined them. This tendency is considered normal in children as a part of their language development, but in adults, such as schizophrenic and aphasic patients, can be respectively a psychopathologic and a brain damage symptom. The product of neologism is also called "nonword", which is a group of letters or speech sounds that looks or sounds like a word, but is not accepted as such by native speakers. Most of the nonwords are nouns or sometimes adjectives but almost never numbers and grammatical items. Despite the common features for this sole named phenomenon, there are salient differences among its kinds. This study aims to find the differences, re-count and classify them in order to obtain better understanding about its nature and function. Investigations on the scarce phenomenon of neologism can inaugurate the grounds to find its bases, causes and consequences. It should be mentioned that this study has not concerned itself to the case of word-approximation, which is sometimes mistaken for neologism and in which, one combines or compounds the available words or morphemes to make a new word for a non-available word for the user, as in "handshoe" for "glove" (Andreasen, 1979) and "reflector" for "mirror" (McKenna, 2007).

\subsection{Characteristics and Grounds of Neologism in Psychiatric and Neurological Patients and Normal Children}

It seems that due to common characteristics in a symptom namely neologism, it must have a common base in given subjects; and because of some differences in its traits, there must be some different elements in its ground.

One of the cases in which neologism occurs is anomic aphasia (anomia) which is a type of aphasia characterized by problems recalling words (particularly nouns and verbs), names, and numbers (Association, 2016). Brain damage may produce the neologisms (Lecours, 1982). Damage to various parts of the parietal lobe or the temporal lobe of the brain causes anomia. In fact the case of aphasic patients with anomia is well-documented in 
the literature. The left posterior temporal cortex is the area involved with the storage of features associated with lexical representations (Martin, 2007; Poeppel \& Hickok, 2004). Precisely, from the neuropathologic view, degenerative disease heavily involving the posterior superior temporal-inferior region should also give rise to neologisms (Rohrer, Rossor, \& Warren, 2009; Warren, Wise, \& Warren, 2005). In general, damage to the left arcuate fasciculus is known to cause anomia. Anomia is one of the grounds which conduce to neologism production. Aphasic patients adapt to this functional impairment (anomia) by substituting a neologism when their lexical search fails (Butterworth, 1979).

Beside anomia which has directy a neurologic cause, a psychopathic ground may lead to neologism. In some of schizophrenic patients with positive symptoms whose brain doesn't show any damage, neologism is seen, however according to the previous studies on schizophrenics with positive symptoms (Thompson et al., 2001), neologism may be related to neuro-developmental abnormalities and decrease of the grey matter volume of their brains as well. Moreover the studies on the active areas of brain for some delusions in schizophrenic patients may lead us to result its relation to neologism in this group. For instance, Tonkonogy \& Puente (2009) suggest that the grandiose delusions are frequently and almost certainly related to lesions of the frontal lobe, and also frontotemporal is involved in patients with grandiose delusions; thus it may have role in occurrence of neologism in the subjects who had this type of delusion. Nelson (2005) expresses grandiose delusions have an important role to sustain or increase the self-esteem of patients. Also Smith, Freeman, \& Kuipers (2005) declare grandiose delusion as defense of the mind against lower self-esteem and depression. Then the psychological aspect seems to have greater role for neologism in schizophrenic patients.

In Children, neologism is seen in a phase of their language acquisition. As mentioned before, most of the studies on neologism, especially in children, concern all of its type but the purest one (without any existing base) which occurs rarely and is much more infrequent, or might be neglected, as the parents and handlers often are unfamiliar with this phenomenon. Children invent neologism to name their image of things, states and actions. Whenever they need a word but do not have it in their lexicon, they fill their lexical gap with their nonword and until developing their lexicon, they make their own vocabulary; and fascinatingly persuade the others to accept their nonword as a word.

\subsubsection{The Relevant Scholarship}

There are some investigations performed into neologism in schizophrenics or in Wernicke's and/or conduction aphasic patients (Butterworth, 1979; Chaika \& Lambe, 1986; Forrest, 1969; Friston \& Frith, 1995; LeVine \& Conrad, 1979) on schizophrenia (Anzaki \& Izumi, 2001; Momeni \& Ebrahimi Rad, 2014; Rohrer et al., 2009) on conduction aphasia).

Some studies on normal children's neologism has been done, however almost all are focused on word-approximation which is not an utter genesis coinage (completely creation without any existing base). Among them investigations of Clark (1982, 1983, 1995), Bushnell \& Maratsos (1984), Ekmekci (1987, 1988) and Motsiou (2012) on derivational and/or compounding word-formation processes, can be mentioned. It seems there has not been any linguistic research done on normal children's neologisms devoted to the genesis coinage so far, unless in a comparative study done by Momeni \& Raghibdoust (Momeni \& Sh., 2012).

There are very few comparative studies about neologism. One of the most comprehensive ones was conducted by A. Lecours \& Vanier-Clément (1976) in which they found that some paraphasias and neologisms in both schizophrenia and jargon aphasia were indistinguishable from each other linguistically, but the nature of many schizophrenic neologisms for being bizarre, differed from the dysphasic ones, in that, according to the researchers, they were based on unusual words.

In another research, Moriyama \& Nakao (1989) compared the neologisms of their three Japanese schizophrenic patients with aphasic neologisms reported in Japanese literature, and found some differences between the nature of the two groups of neologisms based on the dual writing system of kanji (Chinese characters, ideogram) and kana (phonetic characters, syllabogram).

Stenneken, Hofmann, \& Jacobs (2008) in their comparative analysis of neologisms in German aphasic jargon patients and in standard German language found some similarities with respect to phoneme inventory, phonotactics, and phoneme frequency distributions.

From a neuro-anatomical point of view, some studies on schizophrenic patients indicate neuro-developmental abnormalities in brain and loss of grey matter. In the research of Thompson et al. (2001), patients showed a specific, wave-like pattern of loss that began in the parietal cortices and progressed over the following years to affect frontal and temporal regions. Faster loss in the temporal cortices is associated with more severe positive 
symptoms. The decrease of grey matter volume is reported to be up to $25 \%$ in some areas. Despite this, Chaika \& Lambe (1986) suggest that the patients have access to their lexicon, as the pathway of connection between sounds (phonological units) and meaning (cognitive aspect) is intact.

Conduction aphasia is generally reported due to damage in the parietal-insular area, supramarginal gyrus of the left hemisphere and arcuate fasciculus. The neuropathology of conduction aphasic patients involves the posterior superior temporal lobe of the left hemisphere. According to Rohrer et al. (2009) functional disconnection between stored lexical representations and the language output pathways could lead to aberrant or random activation of phonemes in neologistic jargon, due to damage involving a key interface for linking stored lexical templates with verbal output in the posterior superior temporal-inferior parietal region. Catani \& de Schotten (2012) in their "Atlas of human brain connections" have shown the presence of two pathways between Wernicke's area and Broca's area. Damage to a deep pathway which connects these two regions may produce conduction aphasia.

In normal children, from the neurological point of view, we have not found any research on their neologism, but some findings may lead us to a logical reason in this regard. According to Kolb \& Fantie (2009) by 2 years of age there is little neocortical neural cell division and most cells have migrated to their final location in the cortical laminae. The major changes that occur between the ages of 2 and 12 years are in the interconnection of neurons, largely through a decrease in the total number of synapses as well as an increase in the complexity of their dendritic arborizations. Between 15 and 24 months, an increase in the density of the neuropil is seen. Given the correlation between language development and maturation of the language areas, language development may be constrained, at least in part, by the maturation of these areas'. Hence, due to immaturity of the brain neurological structure in children, neologism, also from this viewpoint can be considered as a phase of their language development.

Considering the overall findings of the various investigations, it seemed that the phenomenon of neologism created by different groups of subjects could be classified on the basis of similarities and differences from different viewpoints. Further examinations revealed that linguistic, psychological and neurologic factors could somehow be involved in occurrence of neologism.

\subsection{Neologism from Semiotic Perspective}

From semiotic point of view, the neologisms made by the subjects however have the pattern of sign (signifier signified and signification), as they have not sign-function (Eco, 1986; Hjelmslev, 1928), therefore they are not "sign"; but anyway, they are downright physical entity with individual psychological reality.

Schizophrenia is a semiotic disorder, although not the core impairment underlying the schizophrenic problems (Harrow, Prather, \& Lanin-Kettering, 1986). The frame of sign pattern coined by schizophrenics in an idiosyncratic form is correct. Hence the schizophrenic patients create an interim, instantaneous and significant, as well as intentional system for their nonwords.

Aphasic patients, due to conduction aphasia, suffer from anomia. However they understand the verbal signs when hear/listen or see/watch the matters, they cannot retrieve the signifiers from their lexicon. When we use the stored words of our lexicon for naming the things, we identify the target signified with the stored signified in our lexicon and then retrieve the signifier (Troyer, 2000).

Anyway, reports or main studies on this type of neologism are very rare. From neurolingistic point of view, its function must be more pervasive in the brain. For instance, neologism as a matter of semiotics, regarding two folds of its coin, may conform to the issue of Mitchell \& Crow (2005), who assert on the role of the "neglected" right hemisphere of the brain in language, that "Language is bi-hemispheric: if phonological engrams are segregated to the left this allows some part of their associations to be segregated to the right.

\subsection{Volition, Awareness and Hesitation}

Neologism in conduction aphasic patients, because of anomia is involuntary and unconscious in its primary stage; but it seems that along with recovery, the patient becomes aware of the problem. That may be why these patients several months post-onset, does "conduite d'approche" (Goodglass \& Kaplan, 1983), a self-correction mechanism by repeating to find (and produce) the correct form of the target word (Franklin, Buerk, \& Howard, 2002; Köhler, Bartels, Herrmann, Dittmann, \& Wallesch, 1998; Stark \& Viola, 2008). Pause in producing of neologism in aphasic patients shows their hesitation in this process (Butterworth, 1979). Hesitation seems to be distinctive in this type of neologism between the different groups.

Since in schizophrenic patients, so that mentioned before, neologism seems to be used to as a strategy of defense mechanism against low self-esteem and depression, it must be created voluntarily and consciously. So, this group 
of individuals makes it without hesitance.

Children seem to be aware of their innovation for bizarre nonwords which are quite voluntary and often are made in their egocentric speech, but for the necessary nonwords, they extemporize and use them frequently. It is evident that they experience shortage of lexical words in their lexicon. This causes the child to resolve this problem by using neologisms. Lexicalizing the nonwords by children seems to be as a strategy on the one hand to make up the shortage of their lexicon (for the quotidian words) and on the other hand to specify their images (for their fantastic nonword).

\subsection{The Objectives of the Study and Research Questions}

The present research deals with three questions: 1) is there any difference among the nature of neologism in these groups? 2) What are the main features of neologisms in schizophrenics, aphasic patients and normal children from linguistic, neurological and psychological perspectives? And 3) what is the function of neologism in the three mentioned groups.

As a hypothesis related to these questions, it is assumed that some differences exist in the same type of neologism in the schizophrenic individuals with positive symptoms, conduction aphasic patients and normal children. The main features of the neologism in them must be different in nature due to its grounds and causes. Linguistic, neurological and psychological grounds help to find its features in different groups.

Elicitation of the resemblances and segregations in neologism of the three groups, and classification of the features facilitate to identify the nature and function of neologism in case of each group.

\section{Method}

\subsection{Participants Characteristics}

To determine the nature of the neologism in schizophrenics, aphasic patients and normal children, three Persian-speaking individuals from each group were examined as follow (Subjects are described in Table 1).

Table 1. Demographic characteristics of the subjects

\begin{tabular}{lllllll}
\hline & Schizophrenics & \multicolumn{3}{c}{ Aphasic patients } & Children \\
\hline Gender & Male & Female & Male & Female & Male & Female \\
numbers & 1 & 1 & 1 & 1 & 3 & 2 \\
\hline age & 56 (yrs.) & 35 (yrs.) & 80 (yrs.) & 61 (yrs.) & $20-40$ months \\
Education (yrs.) & 5 & 14 & 0 & 6 & - \\
\hline
\end{tabular}

The schizophrenic patients included a woman ( 35 yr., with 5 yrs. education) and a man (56 yr. with bachelor's level) in acute stage meeting DSM-IVTR criteria for schizophrenia with positive symptoms.

The aphasic subjects were two conduction aphasic patients: 1) a 61 year-old right-handed woman who was tested 12 mounts post-onset. 2) An 80 year-old right-handed illiterate man who was tested 45 days post-onset. Both patients suffered from a hemorrhagic stroke affected the left temporoparietal (according to their MRI).

Neologism is not so prevalent in children. The nurses of the referred kindergartens were not familiar with such a phenomenon in their kids; thus the data were gathered from daily spontaneous speech of 5 children ( 3 boys and 2 girls) with the ages 20 to 40 months old to their family members between 3 to 5 years before this paper and these subjects have been followed up to this time.

\subsection{Sampling Procedures}

The two schizophrenic patients were selected from the Razi and the Roozbeh psychiatric hospitals in Tehran, Iran, were the only individuals within the 22 patients with positive symptoms who produced neologisms. Queries from some specialists during the study to find other subjects with the same symptoms failed, since it occurs very scarcely. The data were obtained from the subjects' spontaneous speech with the researcher, in 3 sessions, in a period of 4 weeks. The meetings were twosome, face to face and the questions occurred during the interviews. Both of the subjects had grandiose delusion.

Both aphasic subjects had referred to the central hospital to Tonekabon City. At the time of testing, both had conduction aphasia with sever problem in repetition, and produced neologisms. To obtain the appropriate data, a simple oral picture-naming test (Nili Pour, 2011) was administrated. The interview took about one hour for each patient and was audio recorded. Some of the pictures were tested 2 or 3 times to find whether they reuse their nonword or not. 
The five children were from one of the kindergartens in Tonekabon City. At first, 20 children were selected but just five children represented the instances of neologism.

\section{Results}

The samples of the neologisms produced by each group of subjects are presented in tables 2 to 4 . The data were observed, and then the general and the linguistic characteristics of them were extracted, classified and explained.

Table 2. The schizophrenic patients' nonwords

\begin{tabular}{lll}
\hline Nonwords & Target words & Meanings according to the patients' descriptions \\
\hline ânkik, tâtik, sâyvonvizi & - & names for courses of diploma or university \\
eskõn & - & a kind of microbe \\
vânzâd & - & evil, malicious \\
ânibâl & - & Solar \\
âstipens & - & A brilliant brain by studying and watching movies. \\
zâkbentokors & - & expectation from a new world \\
âlkânis & - & a kind of biologic cell \\
muj̣ge & - & each chapter of a scientific book \\
\hline
\end{tabular}

Table 3. The aphasic patients' nonwords

\begin{tabular}{lll}
\hline Nonwords & Target words & Picture stimulus \\
\hline mark & kolah & hat \\
hole & qurbâqe & frog \\
bauk & âyene & mirror \\
dox & limu & lemon \\
doxmad & nârengi & tangerine \\
qor & xodkâr & pen \\
se & mix & nail/peg \\
ružgam & xarguš & rabbit \\
box/por & xers & bear \\
vazimaela & susmâr & crocodile \\
kareš & babr & tiger \\
gelan & fil & elephant \\
lâban & anâr & pomegranate \\
žâmâzetâ & porteqâl & orange \\
Čâqer-qeqer & Qâšoq o čangâl & spoon and fork \\
\hline
\end{tabular}

Table 4. The children's nonwords

\begin{tabular}{lll}
\hline Nonwords & Target word & English meaning \\
\hline gamely & Porteqal & orange \\
qezmez (̌̌odan) & xab raftan & tingling (of the feet) \\
qoloppe & Barjastegi & swelling \\
âfânde & Âšpazxâne & open kitchen \\
kânik (kardan) & - & doing the favorite work \\
light verb & - & something from the space \\
pârnksun & Xiyar & cucumber \\
dabu & Mâšin & car \\
hânâ/didid/handed & Tup & ball \\
zâ & &
\end{tabular}

General characteristics of the neologisms:

\section{Occurrence}

For the frequency of the neologism in the three groups, the data showed that the schizophrenic patients and the children produced their nonwords occasionally, but the aphasic patients used neologisms frequently, continual and abundantly. 


\section{Usage}

The schizophrenic and aphasic patients did not reuse their nonwords, whereas the children often reused them.

\section{Volition, awareness and hesitation}

Neologism in schizophrenic patients seems voluntary. Not only the patients made nonwords as if they were scientific or specific words, but also the neologisms simply sounded real words for the hearer.

Neologism in aphasic patients seemed to be involuntary. The male patient whose stroke had happened recently was unaware of his problem. But the other subject with earlier stroke was almost aware. Her family said that she spoke fluently but almost incomprehensible (she had jargon aphasia), but gradually she noticed her problem, trying to correct them. Both of the subjects made nonwords with hesitation and sometimes they changed some phonemes in their nonwords such as vowels, or substituted consonants with common features like [b] and [v] at the same time.

Neologism in children seems to be involuntary for quotidian nonwords but voluntary for the fantastic (imaginary) ones, nevertheless they did not demonstrate hesitation while producing.

Linguistic characteristics

\section{Semiotics}

Concerning the production of neologism as "nonword" rather than word, the issue must be discerned from an idiosyncratic sign. In this regard, for the children, the sign system function based on signification between signifier and signified was accurate because they always reused the same nonword as the target word. In the aphasic patients a disturbance was obvious in signification processing (connection of signifier and signified) or specially in finding the signifier, as one of them (the 61 year old patient) hesitantly and stressfully often expressed: "midunam; midunam; in ... e (I know; I know; it's...)", and made a nonword instead. In the schizophrenic patients, there was a provisional signification between signifier and their imaginary signified, though once used.

\section{Semantics}

In the samples, two distinct semantic characteristics of neologisms are recognized: Some of the nonwords are made as substitutes for real words with a common meaning or concept which are called "quotidian neologisms" here. The other type of nonwords called "bizarre" here, are produced as an imagery concept in the subject's mind.

As table 2 shows, the schizophrenic patients only have produced the bizarre type of neologism. It reveals that this group does not need to produce the nonwords; they must have other reason(s) to make them, though. A psychological reason has been assumed under discussion topic.

The aphasic patients, unlike schizophrenics, produced the quotidian neologisms. However the test was focused on picture naming, based on their family answer, they did not make any nonword for imaginary concept; in fact they produced them just for compensating the needed word and they did not speak unless they had to. (Table 3)

Table 4 shows, the children uttered both types of bizarre and quotidian neologism; the former for the imaginary concepts and the latter for the compensating of the shortage of their lexicon.

\section{Morphology}

All the neologisms in the 3 groups of subjects were lexical categories of Noun and Adjectives, and no non-lexical (grammatical) item was produced. Also, the neologisms of all the 3 groups were produced via the coinage process. All the nonwords had a simple structure, and thus can be said to include only one free pseudo-morpheme; however one of the schizophrenic patients (with elementary literacy) used [i] or [ik] at the end of the name of some scientific courses such as "ankik", "tatik", " optiolâzi" and "tokorânži". The children combined the nonwords with a real light verb to make a compound verb. Moreover, some of the nonwords sounded as onomatopoeia (e.g., "didid" and "handid" which the former has the sound of car's horn; and in the latter, the first syllable has the sound of car's movement and the last syllable sounds the car's horn as well), and some peered synesthetic (like "qezmez" for tingling of the body).

Reusing the nonwords by the children shows that they lexicalize them until they learn the real word in the case of quotidian neologisms, and use the bizarre ones until they overrule their imagines.

\section{Phonotactics and prosody}

The neologisms of all the 3 groups in general were rule-governed at the segmental and supra-segmental levels. 
The only exception was that the children sometimes violated the rules in making their fantastic nonwords; for example, in "pârnksun", the child used a cluster of 3 consonants in the coda position of the syllable (rnk), which does not conform to the syllabic pattern of Persian.

It is worth saying that two of the schizophrenic patients, when pretending to apply foreign words, could easily imitate the exact manner of the pronunciation and even the phonemes of the simulative language; for example, a patient (well educated and familiar with foreign languages) who imagined himself as the principal of an oncologic institute in France, named it [lo'âp], so he named [œžœdepã] his hospital, which meant "tsar" for him, and a cancer treatment device was named [dœetâž] by him; also the neologisms of another patient with elementary literacy, were [optiolâzi] and [tokorânži] for the name of scientific courses which apparently seem to be real scientific terms.

\section{Discussion}

The results indicate some of the main features in the neologism of the three groups. Differences in its general and/or linguistic characteristics can be seen. Neologisms in each group demonstrate particular features due to different causes.

Rarity of neologism in schizophrenic patients and children refers to their satiety to words; unless in scarce occasions for children who want to fulfill an urgent need. In contrast, the frequency and abundance of neologism in anomic patients represents their necessity to compensate their shortage of needed words.

Once use of the coined nonwords by the schizophrenic and the aphasic patients could indicate a common inefficiency, however for different reasons (the former for a psychopathic and the latter for a neurologic cause). Children produce neologism as a necessary word, though provisional, they reuse them to convey their massage by creation a communicative system.

The schizophrenics (most probably with positive symptoms) are cognizant about their neologism as a capability to make a "word" because they make them fluently, according to the linguistic knowledge of their intended target language, and without any hesitation whenever they want. In contrast, the aphasic patients with anomia have no way to communicate but using the unconscious strategy of neologism with having hesitation. But in children, the more they seem alert and communicative or even somehow talkative, the more they produce neologisms; however they seem to do it unwittingly for quotidian words and probably intentionally for the bizarre (imaginary) ones (since they utter them timidly).

It seems that the neologism is voluntary and intentional in schizophrenic patients, because they have control on the nature of this strategy. As evidence, the 35 year old woman patient, in the first visit, introduced herself with an incomprehensible name (even after three times repeating) and with another surname. She misrepresented herself as a 13 year old girl. During this visit, she deliberately spoke unclear and treated so deceitfully that it seemed she had deficit in pronunciation. She also did not produce any obvious neologism. In contrast, during the second meeting, she posing herself as a scholar, she interviewed clearly, although incoherent and full of neologisms. This case may show that she knew how and when to produce neologism.

From neurolinguistic aspect, although there was no neuropathological record of schizophrenic subjects, but the bizarre nature of nonwords of schizophrenic patients with positive symptoms indicates that their strange imaginary concepts may be attributed to their hallucinations and delusions, specially the grandiose one. It seems they often produce neologisms when they pontificate, do jactitation and tend to suggest that they know something which is incomprehensible for the others; this usually happens when they feel their addressee is a high status individual, probably due to having the impression that they are rejected by the others. Thus, neologism, for schizophrenics may be a strategy as a defense mechanism against their sense of being rejected. These findings confirm the issues of Nelson (2005) and Smith et al. (2005).

The reports of our conduction aphasic patients' MRI concerning hemorrhage in left temporoparietal area are in conformity with the aforesaid issues of Martin (2007), and Poeppel \& Hickok (2004).

From semiotic point of view, the observance of all points in neologism creation by schizophrenic patients so sound that misleads a dilettante interlocutor to discern the nonwords from the real ones. This shows the accuracy and dominance of schizophrenic individuals to construct quasi signs which seems to be opposed to the statement of Harrow et al. (1986). In aphasic patients if we consider a form of signification processing occurs in retrieving and identification of the target signified with the signified stored in lexicon to refer the sign by producing its signifier, thus it could be assumed that the structure of signification in this case is damaged. The children's imaginary neologism demonstrates the same semiotic characteristic as schizophrenics' neologism, but in the case of the quotidian nonwords, they create their own words. In fact it is only the children who use their excellent 
linguistic strategy to make a sign, because they reuse them and persuade their associates to learn their nonwords as words.

In a summary of the general outcomes of this study, table 5 presents a classification of the discussed features of the neologism phenomenon in the 3 experimental groups.

Table 5. Comparative table of neologism in the three groups of subjects

\begin{tabular}{|c|c|c|c|c|}
\hline Aspects & Characteristics & $\begin{array}{l}\text { Schizophrenic patients } \\
\text { (with positive symptoms) }\end{array}$ & Conduction aphasic patients & Children \\
\hline \multirow[t]{5}{*}{ linguistic } & Semiotic & accurate signification system & $\begin{array}{l}\text { disturbance in signification } \\
\text { processing (connection of } \\
\text { signifier and signified) }\end{array}$ & accurate signification system \\
\hline & Semantic & bizarre & quotidian & more quotidian, less bizarre \\
\hline & phonotactic & $\begin{array}{l}\text { rule-governed at the phonetic } \\
\text { and phonological levels }\end{array}$ & $\begin{array}{l}\text { rule-governed at the phonetic } \\
\text { and phonological levels }\end{array}$ & $\begin{array}{l}\text { rule-governed at the phonetic } \\
\text { and phonological levels in } \\
\text { quotidian } \\
\text { nonwords/rule-violated in } \\
\text { fantastic nonword }\end{array}$ \\
\hline & $\begin{array}{l}\text { use of the } \\
\text { nonword }\end{array}$ & once using & once using & reusing \\
\hline & lexicalization & never & never & $\begin{array}{l}\text { temporary lexicalized } \\
\text { nonwords until learning the } \\
\text { real words }\end{array}$ \\
\hline neurological & Cause & $\begin{array}{l}\text { neuro-developmental } \\
\text { abnormalities }+ \text { decrease of } \\
\text { the grey matter volume }\end{array}$ & $\begin{array}{l}\text { Damage to the posterior } \\
\text { superior temporal-inferior } \\
\text { parietal regions+lesions to the } \\
\text { arcuate fasciculus }\end{array}$ & $\begin{array}{l}\text { immaturity of the brain's } \\
\text { neurotic structure }\end{array}$ \\
\hline \multirow[t]{7}{*}{ psychological } & cause & $\begin{array}{l}\text { Positive symptoms specially } \\
\text { grandiosity delusion }\end{array}$ & anomia & $\begin{array}{l}\text { Shortage of the } \\
\text { lexicon+fantasy }\end{array}$ \\
\hline & $\begin{array}{l}\text { Objective and } \\
\text { intention }\end{array}$ & $\begin{array}{l}\text { mostly self-assertion and } \\
\text { pontification }\end{array}$ & provision the needed words & provision the needed words \\
\hline & Motivation & $\begin{array}{l}\text { defense mechanism by using } \\
\text { their language creation } \\
\text { ability }\end{array}$ & $\begin{array}{l}\text { Compensation of failing the } \\
\text { retrieval the target word }\end{array}$ & $\begin{array}{l}\text { Language development }+ \\
\text { creation }\end{array}$ \\
\hline & occurrence & occasionally & frequently and abundantly & occasionally \\
\hline & Volition & voluntary & involuntary & $\begin{array}{l}\text { involuntary for quotidian } \\
\text { nonwords / voluntary for } \\
\text { fantastic nonwords }\end{array}$ \\
\hline & Awareness & consciously & $\begin{array}{l}\text { unaware in the early time of } \\
\text { stroke, gradually almost } \\
\text { consciously }\end{array}$ & $\begin{array}{l}\text { unaware for quotidian and } \\
\text { aware for bizarre nonwords }\end{array}$ \\
\hline & hesitation & promptly & with hesitation & promptly \\
\hline
\end{tabular}

\section{Conclusion}

Neologism, for its scarce occurrence, is rarely reported; even though it gives a lot of information from different aspects of its nature and function. In this research, the nature of neologism in three groups including schizophrenic subjects with positive symptoms, conduction aphasic patients affected a stroke, and normal children was investigated from linguistic, neurological and psychological aspects.

The main features of neologisms obtained from the three groups have been investigated from linguistic, neurological and psychological perspectives.

Neologism in different given group of subjects, despite some similarities, demonstrates obvious and determinative differences. The data showed the differences; and a classification of the characteristics of neologism in the three given groups of subjects has been presented.

Neologism seems to operate in schizophrenics (with positive symptoms and specially suffering from grandiosity) as a strategy against their sense of being rejected. Hence, it functions as defense mechanism. In aphasic patients, neologism occurs to compensate their shortage of needed words. In children, neologism has two functions: it is a 
phase of both their language and their cognition development, with different executions. It seems the finding can provide practical and applicative information about a very rare but determinant phenomenon.

Further studies on each of the characteristics of neologism from different angles and on various languages may provide a more precise classification of the diversity of neologism. It is evident that the more findings from its nature provide the more extensive areas in related domains.

\section{Acknowledgments}

We appreciate Dr. Mohammad Reza Mohammadi, the Psychiatrist Professor of Tehran University of Medical Sciences whose favors made feasible this research on schizophrenic patients of Razi and Roozbeh Psychiatric Hospitals, and thank the neurologists Dr. Rahmat Jirdehi and Dr. Masoud Ebrahimi Rad for introducing the aphasic patients. Also we want to give thanks for the aphasic patients and their family for their cooperation during the interviews, and dear parents of the children for helping to gather the needed data.

\section{References}

Andreasen, N. C. (1979). Thought, language, and communication disorders: I. Clinical assessment, definition of terms, and evaluation of their reliability. Archives of general Psychiatry, 36(12), 1315-1321. http://dx.doi.org/10.1001/archpsyc.1979.01780120055007

Anzaki, F., \& Izumi, S. (2001). Differences between conduction aphasia and Wernicke's aphasia. The Tokai Journal of Experimental and Clinical Medicine, 26(2), 45-61.

Bushnell, E. W., \& Maratsos, M. P. (1984). Spooning and basketing: children's dealing with accidental gaps in the lexicon. Child Dev, 55(3), 893-902.

Butterworth, B. (1979). Hesitation and the production of verbal paraphasias and neologisms in jargon aphasia. Brain and language, 8(2), 133-161. http://dx.doi.org/10.1016/0093-934X(79)90046-4

Catani, M., \& de Schotten, M. T. (2012). Atlas of human brain connections. Oxford: Oxford University Press. http://dx.doi.org/10.1093/med/9780199541164.001.0001

Chaika, E., \& Lambe, R. (1986). Is Schizophrenia a Semiotic Disorder? Replies to Harrod. Schizophrenia Bulletin, 12(1), 15-19. http://dx.doi.org/10.1093/schbul/12.1.14

Clark, E. V. (1982). The young word maker: a case study of innovation in the child's lexicon. Language Acquisition: The State of the Art, 390.

Clark, E. V. (1983). Convention and contrast in acquiring the lexicon. Concept development and the development of word meaning (pp. 67-89). Berlin: Springer. http://dx.doi.org/10.1007/978-3-642-69000-6_5

Clark, E. V. (1995). The lexicon in acquisition (Vol. 65). Cambridge: Cambridge University Press.

Eco, U. (1986). Semiotics and the Philosophy of Language. Indiana: Indiana University Press.

Ekmekci, O. (1987). Creativity in the language acquisition process. Studies on Modern Turkish, 203-210.

Ekmekci, O. (1988). Coinage of Words in Child's Lexicon in Acquiring Turkish. Paper presented at the Proceedings of the International Linguistics Congress.

Forrest, D. V. (1969). New words and neologisms: With a thesaurus of coinages by a schizophrenic savant. Psychiatry, 32(1), 44-73.

Franklin, S., Buerk, F., \& Howard, D. (2002). Generalised improvement in speech production for a subject with $\begin{array}{llll}\text { reproduction } & \text { conduction } & \text { aphasia. }\end{array}$ http://dx.doi.org/10.1080/02687030244000491

Friston, K. J., \& Frith, C. D. (1995). Schizophrenia: a disconnection syndrome. Clin Neurosci, 3(2), 89-97.

Goodglass, H., \& Kaplan, E. (1983). The Assessment of Aphasia and Related Disorders (2nd ed.). Philadelphia, PA: Lea \& Febiger.

Harrow, M., Prather, P., \& Lanin-Kettering, I. (1986). Is Schizophrenia a Semiotic Disorder? Replies to Harrod. Schizophrenia Bulletin, 12(1), 15-19. http://dx.doi.org/10.1093/schbul/12.1.15

Hjelmslev, L. (1928). Principes de grammaire générale (Vol. 1). Kommissionaer: Munksgaard.

Köhler, K., Bartels, C., Herrmann, M., Dittmann, J., \& Wallesch, C. W. (1998). Conduction aphasia-11 classic cases. Aphasiology, 12(10), 865-884. http://dx.doi.org/10.1080/02687039808249456 
Kolb, B., \& Fantie, B. D. (2009). Development of the child's brain and behavior. Handbook of clinical child neuropsychology (pp. 19-46). Berlin: Springer. http://dx.doi.org/10.1007/978-0-387-78867-8_2

Lecours, A. R. (1982). On neologisms. Perspectives on Mental Representation, 217-247.

Lecours, A., \& Vanier-Clément, M. (1976). Schizophasia and jargonaphasia: A comparative description with comments on Chaika's and Fromkin's respective looks at "schizophrenic" language. Brain and Language, 3(4), 516-565.

LeVine, W. R., \& Conrad, R. L. (1979). The classification of schizophrenic neologisms. Psychiatry, 42(2), 177-187.

Martin, A. (2007). The representation of object concepts in the brain. Annu. Rev. Psychol., 58, 25-45. http://dx.doi.org/10.1146/annurev.psych.57.102904.190143

McKenna, P. J. (2007). Schizophrenia and related syndromes. London, New York: Routledge.

Mitchell, R. L., \& Crow, T. J. (2005). Right hemisphere language functions and schizophrenia: the forgotten hemisphere? Brain, 128(5), 963-978. http://dx.doi.org/10.1093/brain/awh466

Momeni, F., \& Ebrahimi Rad, R. (2014). An investigation on neologism in conduction aphasia: a case study. Paper presented at the the 1st national conference of neuro-psycholinguistics, "Iran society of linguistics" \& "Institute for humanities and cultural studies", Tehran, Iran.

Momeni, F., \& Raghibdoust, Sh. (2012). Comparison of neologisms in aphasia, schizophrenia and children language. Paper presented at the Biennial meeting of World Federation of Neurology Research Group on Aphasia and Cognitive Disorders, Hyderabad, India.

Moriyama, N., \& Nakao, H. (1989). Schizophrenic neologism versus aphasic neologism: characteristics in writings of Japanese schizophrenic patients. Psychiatry and Clinical Neurosciences, 43(2), 137-142. http://dx.doi.org/10.1111/j.1440-1819.1989.tb02561.x

Motsiou, E. T. (2012). Lexical innovations (neologisms) in children's speech: evidence from Greek. Contrastive Linguistics, 2(22-32).

National Aphasia Association. (2016). Anomic Aphasia. Retrieved from http://www.aphasia.org/aphasia-resources/anomic-aphasia/

Nelson, H. E. (2005). Cognitive-behavioural therapy with delusions and hallucinations: A practice manual. Cheltenham, UK: Nelson Thornes.

Nili Pour, R. (2011). Persian Aphasia Naming Test. Tehran: University of Social Walfare \& Rehabilitation Sciences.

Poeppel, D., \& Hickok, G. (2004). Towards a new functional anatomy of language. Cognition, 92(1), 1-12. http://dx.doi.org/10.1016/j.cognition.2003.11.001

Rohrer, J. D., Rossor, M. N., \& Warren, J. D. (2009). Neologistic jargon aphasia and agraphia in primary progressive aphasia. Journal of the Neurological Sciences, 277(1), 155-159. http://dx.doi.org/10.1016/j.jns.2008.10.014

Smith, N., Freeman, D., \& Kuipers, E. (2005). Grandiose delusions: an experimental investigation of the delusion as defense. The Journal of Nervous and Mental Disease, 193(7), 480-487. http://dx.doi.org/10.1097/01.nmd.0000168235.60469.cc

Stark, J., \& Viola, M. S. (2008). Successive Approximations at Producing Sentences-Longitudinal Analysis of Conduite d'Approche Behavior Observed in a Broca's Aphasic. Clinical Aphasiology Conference.

Stenneken, P., Hofmann, M. J., \& Jacobs, A. M. (2008). Sublexical units in aphasic jargon and in the standard language: Comparative analyses of neologisms in connected speech. Aphasiology, 22(11), 1142-1156. http://dx.doi.org/10.1080/02687030701820501

Thompson, P. M., Vidal, C., Giedd, J. N., Gochman, P., Blumenthal, J., Nicolson, R., ... Rapoport, J. L. (2001). Mapping adolescent brain change reveals dynamic wave of accelerated gray matter loss in very early-onset schizophrenia. Proceedings of the National Academy of Sciences, 98(20), 11650-11655. http://dx.doi.org/10.1073/pnas.201243998

Tonkonogy, J. M., \& Puente, A. E. (2009). Localization of clinical syndromes in neuropsychology and neuroscience. New York: Springer Publishing Company. 
Troyer, A. K. (2000). Normative data for clustering and switching on verbal fluency tasks. Journal of Clinical $\begin{array}{llll}\text { and } \quad \text { Experimental } & \text { Neuropsychology, }\end{array}$ http://dx.doi.org/10.1076/1380-3395(200006)22:3;1-V;FT370

Warren, J. E., Wise, R. J., \& Warren, J. D. (2005). Sounds do-able: auditory-motor transformations and the posterior temporal plane. Trends in Neurosciences, 28(12), 636-643. http://dx.doi.org/10.1016/j.tins.2005.09.010

\section{Copyrights}

Copyright for this article is retained by the author(s), with first publication rights granted to the journal.

This is an open-access article distributed under the terms and conditions of the Creative Commons Attribution license (http://creativecommons.org/licenses/by/4.0/). 